\section{Immunohistochemical demon- stration of keratins in the epi- dermal layers of the Malayan pangolin (Manis javanica), with remarks on the evolution of the integumental scale armour}

\author{
W. Meyer, ${ }^{1}$ M. Liumsiricharoen, ${ }^{2}$ \\ A. Suprasert, ${ }^{2}$ L.G. Fleischer, ${ }^{3}$ \\ M. Hewicker-Trautwein 4 \\ IInstitute for Anatomy, University of \\ Veterinary Medicine Hannover \\ Foundation, Hannover, Germany \\ 2Department of Anatomy, Faculty of \\ Veterinary Medicine, Kasetsart \\ University, Bangkok, Thailand \\ ${ }^{3}$ Institute of Food Technology and Center \\ of Biotechnology, Technical University \\ Berlin, Germany \\ ${ }^{4}$ Institute for Pathology, University \\ of Veterinary Medicine Hannover \\ Foundation, Hannover, Germany
}

\section{Abstract}

Using immunohistochemistry, the study demonstrates the distribution of keratins (pankeratin with CK1-8, 10, 14-16, 19; keratins CK1, $5,6,9,10$; hair keratins AE13, AE14) in the epidermis of the Malayan pangolin (Manis javani$c a$ ). A varying reaction spectrum was observed for pan-keratin, with body region-dependent negative to very strong reaction intensities. The dorsolateral epidermis exhibited positive reactions only in its vital layers, whereas the abdominal epidermis showed strong positive reactions in the soft two outer strata. The single acidic and basic-to-neutral (cyto)keratins produced clear variations compared to the pan-keratin tinging. For example, CK1 appeared in all epidermal layers of both body regions, except for the ventral stratum corneum, whereas CK5, 6, 9, 10 were restricted to the soft ventral epidermis. Here, distinctly positive reactions were confined to the stratum granulosum, except for CK6 that appeared in the soft stratum corneum. A different staining pattern was obvious for the hair keratins, i.e., positive reactions of AE13 concentrated only in the granular layer of the dorsal epidermis. In the abdominal epidermis, remarkable tinging for AE14 was visible in the stratum basale, decreasing toward the corneal layer, but was also found in the outer root sheath cells of the hair follicles in the ventral body part. Our findings are discussed related to the evolution of the horny dorsal scales of the pangolin, which may have started from the tail root, projecting forward to the head.

\section{Introduction}

New genetic evidence indicates that pangolins are the closest living relatives of the Carnivora with which they form the clade Ferae. ${ }^{1,2}$ Especially rather small groups like the order Pholidota with the only family Manidae are concerned, that consists of one genus (Manis) with eight species and has a special biology. ${ }^{3,4}$ The physical appearance of pangolins is based on large, hardened, plate-like scales found dorsolaterally at the body and the tail, whereas the abdominal body part shows a thick soft stratum corneum and a dense cover of fine hairs. ${ }^{5}$ These scales, which are soft on newborn pangolins but harden as the animal matures, are formed by $\alpha$-keratins and $\beta$-keratins, ${ }^{6,7}$ guaranteeing a high abrasive wear resistance. ${ }^{8}$ If curling up of the animal when threatened, the overlapping scales can act as armour because they are sharp and thus provide extra defense. ${ }^{6}$ In this context it is quite interesting that the water-to-land transition in the stem lineage of tetrapods was associated with a major radiation and functional diversification of keratin genes. These duplications acquired functions that serve rigidity in integumental hard structures and were the prime for subsequent independent keratin diversification in tetrapod lineages. ${ }^{9}$

Realizing this background, our study was aimed to give more detailed information on the construction and development of the epidermis and their products, particularly with regard to the keratin-dependent integumental scale system. Keratins are epithelial-specific intermediate filament proteins that comprise the largest numbers of subtypes classified as acidic or basic (cyto)keratins (acidic type I akeratins: CK 9-20; basic-to-neutral type II akeratins: CK 1-8), and acidic hard hair keratins which are arranged in heterotypic pairs and integrated into multimeric filaments, whereby the precursor cells of hair cortex and nail plate share a major pathway of development, so that the latter group represents a co-expressed keratin pair which can serve as a marker for hair/nail-type epithelial differentiation. ${ }^{10-12}$ Furthermore, intermediate filaments are one of three types of cytoskeletal elements that are essential for cell shape, motility and structural integrity, belonging to a large and diverse gene family, and they are expressed selectively in different specific cell types..$^{12,13}$ Keratinisation, i.e., the mechanical stabilization and integrity of epidermal cells by a multifunctional cytoskeleton is above all based on the intermediate filament keratins with a direct binding to desmosomal proteins. Thus a very solid epidermis is ensured, particularly when the outer layer, the stratum corneum is concerned. ${ }^{12,14,15}$ Based on this fundamental information and an
Correspondence: Prof. Dr. Wilfried Meyer, Institute for Anatomy, University of Veterinary Medicine Hannover Foundation, Bischofsholer Damm 15, 30173 Hannover, Germany. Tel. +49.511 .8567214 - Fax: +49.511 .8567683 . E-mail: wilfried.meyer@tiho-hannover.de

Key words: keratinisation, epidermis, scale evolution, Malayan pangolin, immunohistochemistry.

Acknowledgments: the excellent technical assistance of M. Gaehle and D. Walter is gratefully acknowledged.

Received for publication: 7 July 2013. Accepted for publication: 15 August 2013.

This work is licensed under a Creative Commons Attribution NonCommercial 3.0 License (CC BYNC 3.0).

(C) Copyright W. Meyer et al., 2013 Licensee PAGEPress, Italy

European Journal of Histochemistry 2013; 57:e27 doi:10.4081/ejh.2013.e27

immunohistochemical approach, our study for the first time shows the distribution of important keratins in the epidermis of the Malayan pangolin (Manis javanica), featuring the peculiarity of its integumental scale system. Finally, our observations are used to discuss the evolution of the unique scale armour of the Manidae.

\section{Materials and Methods}

Skin samples from the dorsolateral and the abdominal regions of five adult (two males, three females) and two subadult (sex not determined) animals, which had to be euthanized because of their bad general condition by the colleagues of the Faculty of Veterinary Medicine of the Kasetsart University in Bangkok, could be used for this study conducted with permission of the Thai government. The animals had been confiscated as smuggled goods by officers at the Khao Pratubchang Wildlife Breeding Center, Rachaburi province, Thailand. The material was fixed in $10 \%$ neutral buffered formalin for at least $48 \mathrm{~h}$ at room temperature. After fixation, the samples were carefully dehydrated in a graded series of ethanol, and embedded via xylene in paraffin wax (Paraplast plus, Sigma-Aldrich, Pathuwan, Bangkok, Thailand).

For our purpose, $8 \mu \mathrm{m}$ paraffin sections were deparaffinized in Histoclear (Biozym Scientific GmbH, Hessisch Oldendorf, Germany) and hydrated through descending concentrations of ethanol. Before immunohistochemical staining, several sections from all 
the animals studied were stained with hematoxylin-eosin ${ }^{16}$ for light microscopical structure control. Afterwards, sections of good quality were stained immunohistochemically for the determination of the different keratins studied: pan-keratin (with the following spectrum of acidic and basic-to-neutral (cyto)keratins C1 - 8, 10, 14 - 16, 19), the (cyto)keratins 1, 5, 6, 9, 10, and the hair keratins AE13 (CK 1013; hair cortex), AE 14 (CK 1014; hair shaft) (dilutions 1:50, 1:10, monoclonal, anti-mouse; all Bioprime products, BioLogo, Kronshagen, Germany). Following incubation over night at $4^{\circ} \mathrm{C}$, the reaction was detected by the EnVision ${ }^{\circledR}$ system (DakoCytomation, Hamburg, Germany), using peroxidase-based very sensitive dextran-polymer visualization. One part of the sections was incubated for 30 min in TEC buffer at $90^{\circ} \mathrm{C}$ prior to the reaction.

To conduct the negative controls, the first antibody was omitted and instead the tissue was incubated with PBS / 1\% BSA. In order to exclude the possibility of non-specific binding of the Fc-part of the primary antibody, isotype controls were conducted (see also Hornickel $e t$ $\left.a l .{ }^{17}\right)$. For this purpose, the primary antibody was omitted and replaced by an IgG mouse (Sigma-Aldrich, Munich, Germany) antibody. The respective protein concentration of the antibody was considered, i.e., the IgG mouse antibody was applied in the same protein concentration as the primary antibody. To evaluate non-specific binding potentially caused by sources other than the primary antibody, tissue sections were also stained with just the secondary antibody followed by application of the visualization system.

The microscopic results were documented with a Zeiss Axioskop equipped with a digital camera (Olympus DP70; Olympus Deutschland, Hamburg, Germany); the software Olympus DP-SOFT (version 3.1 and 3.2) was applied for picture analysis.

\section{Results}

As already shown earlier, ${ }^{5}$ the integument of the pangolin is characterized by distinct regional differences comparing the dorsolateral body region, marked by a very hard scaly armour, with the abdominal body region without scales, but with a thick soft stratum corneum. This difference includes a polished surface of the hard scales (Figure 1a), in contrast to the surface of the epidermis of the abdomen, which is only protected by a dense and fine hair coat (Figure 1b). Such typical structural features are also clearly emphasized by our immunohistochemical findings, accordingly demonstrating variations of the keratins or cytokeratins present, as shown in Figures 2,
3 and 4, and summarized in Table 1.

The antibodies against the keratins used exhibited a broad and somewhat varying reaction spectrum related to pan-keratin, with body region dependent negative to very strong reaction intensities (Figure 2). In this context, the dorsolateral epidermis exhibited positive reactions only in its vital layer part combined with a completely negative staining of the corneal layer (Figure 2a), whereas the abdominal epidermis was clearly discernable by its generally positive reactions, including very strong intensities particularly in the stratum spinosum and the soft stratum corneum (Figure 2b).
However, analysing the immunohistochemical staining results of the several acidic and basicto-neutral (cyto)keratins studied, clear variations appeared compared to the pan-keratin tinging. This means that CK 1 could be found in all the epidermal layers of both body regions, except for the ventral stratum corneum (Figure 2 c,d), whereas CK 5, 6, 9, 10 were missing in the dorsolateral epidermis but demonstrable in the soft ventral epidermis (Figure 3 a-d). Moreover, distinctly positive reactions found in the ventral epidermal layers were more or less restricted to the stratum granulosum, except for CK 6 showing a rather
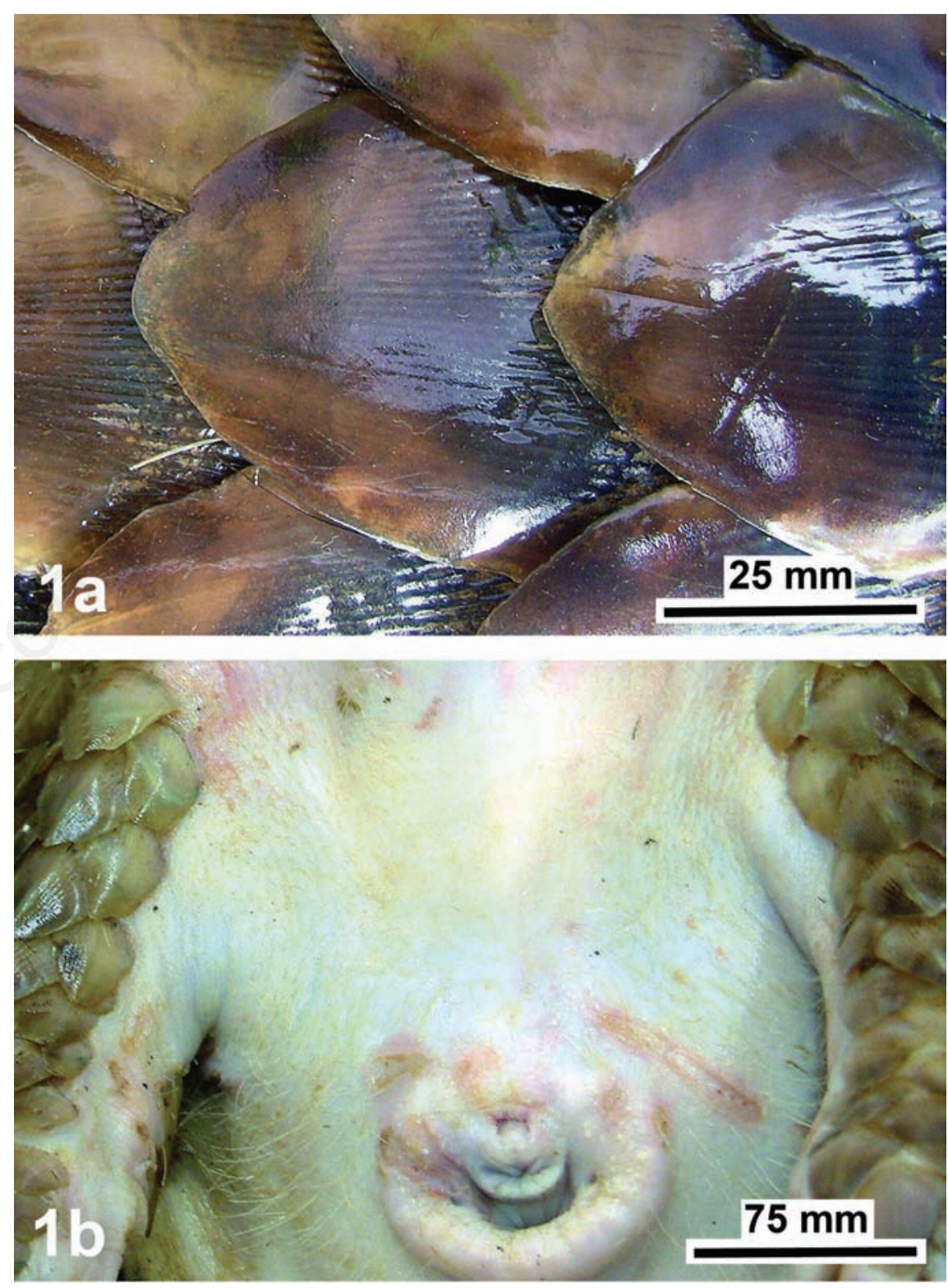

Figure 1. View of the dorsolateral body region (a) with its hard horny scales showing a polished surface, and of the abdominal body region (b) with a dense coat of fine hairs, shown near the anogenital region of the Malayan pangolin (Manis javanica). 
homogeneous tinge also throughout the typical thick and soft stratum corneum (Figure $3 \mathrm{~b}$ ).

A different staining pattern became obvious after applying the antibodies against the hard hair keratins AE13 (CK1013) and AE14 (CK1014). Positive reactions for AE13 were generally restricted to the dorsal epidermis. Here a medium to very strong staining could only be recognized in the stratum granulosum, and became rather inconspicuous in the corneal layer (Figure 4a). In contrast, remarkable tinging for AE14 could be detected with medium to strong intensities exclusively in the stratum basale of the abdominal epidermis, decreasing to weaker reactions in the stratum spinosum or stratum granulosum, and negative results in the stratum corneum (Figure 4b). However, a positive staining for this keratin type was additionally visible in the cells of the outer root sheath of the numerous hair follicles present in the ventral body part (Figure 4c).

\section{Discussion}

Generally, the mammalian epidermis seems to be a paradigm for the understanding of the cytoskeleton from several combinations of type I (a) and II (b) keratins, particularly concerning terminal differentiation related to a massive increase of suprabasal keratins. ${ }^{12,18,19}$ Such development is completed by the stratum granulosum where the viable granular cell is transformed into a nonviable cornified cell as accomplished by the modification and transfer of some components between these cell layers (keratins, profilaggrin, enzymes, lipids, proteins of the CCE) as well as a degradation and loss of others (nucleus, cell organelles, ground substance). ${ }^{20-22}$ This is most important in view of the fact that keratins have major functions to guarantee stability to the epithelial cells under conditions of mechanical stress. Different studies controlling cell fragility after the knockout of important epithelial (cyto)keratins (e.g., CK5, 8, 14, 18, 19) have confirmed that an intact cytoskeleton is also essential to maintain tissue integrity even in the stratum basale. ${ }^{19,23,24}$ Thus, keratins are specific mechanical integrators of space for the epidermis and its appendages, ${ }^{12,18}$ as shown for all vertebrate groups, in particular the terrestrial ones such as reptiles, birds and mammals. In this context, the proctecting dorsolateral integumental scale system (armour) of pangolins is a very good example ${ }^{6}$ although only rarely studied such as concentrating on the abrasive wear behaviour of the surfaces of pangolin scales. ${ }^{7,28}$

From a comparative point of view, the results concerning the (cyto)keratins (acidic type I a-keratins: CK 9 - 20; basic-to-neutral type II a-keratins: CK $1-8$ ) emphasized a broad and varying reaction spectrum, with body region-dependent negative to very strong reaction intensities. This means that the dorsolateral epidermis showed positive reactions only in its vital layer part and a completely negative staining confined to the stratum corneum, whereas the abdominal epidermis was marked by generally positive reactions, including very strong intensities particularly in the soft stratum corneum and the stratum spinosum. These findings confirmed the results for the epithelial keratin types I and II obtained for all the mammalian groups studied until now. ${ }^{12,18,19,25}$

The staining results acquired using antibodies against the hard hair keratins AE13 and AE14 elucidate, indirectly and directly, the close relationship of such keratins to the hair follicle. This means that AE13 stained only the granular cells but not the stratum corneum and the scales of the dorsolateral epidermis, whereas AE14 tinged with strong to weak reac-
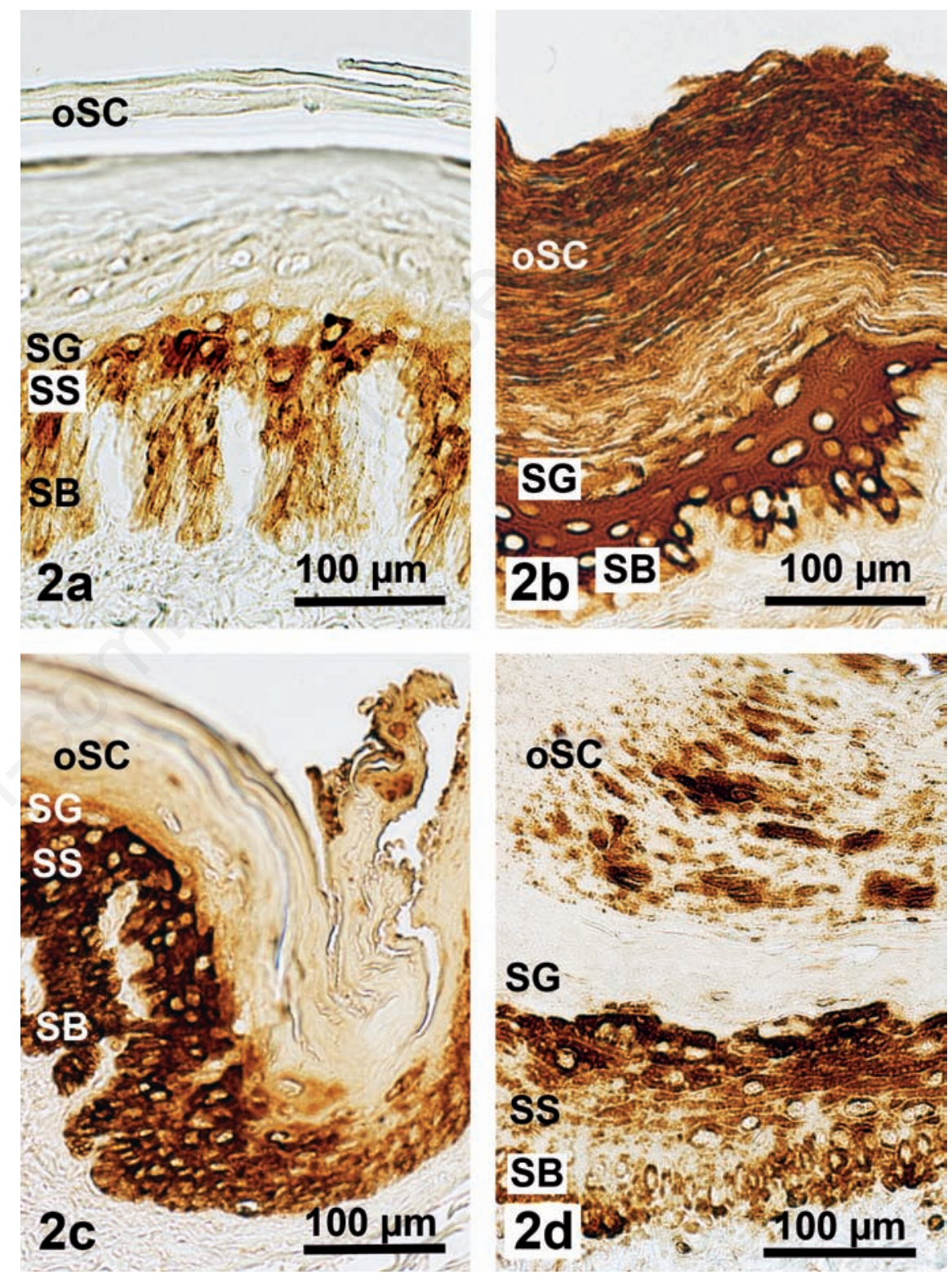

Figure 2. Demonstration of a standard spectrum of epithelial (cyto)keratins in the epidermis of the Malayan pangolin; reactions of pan-keratin (a) in the dorsolateral scale region and (b) in the scale-free ventral body region; reactions of CK 1 are obvious (c) in the scale hinge part of the dorsal body region, and (d) in the ventral body region; strong staining is best visible in the vital epidermis; DAB visualization. SB, stratum basale; SS, stratum spinosum; SG, stratum granulosum; oSC, outer stratum corneum.). 
Table 1. Distribution of keratins in the epidermis of the pangolin.

\begin{tabular}{|c|c|c|c|c|c|}
\hline $\begin{array}{l}\text { Epidermal } \\
\text { layers/keratins }\end{array}$ & Stratum basale & Stratum spinosum & $\begin{array}{l}\text { Stratum } \\
\text { granulosum }\end{array}$ & $\begin{array}{c}\text { Stratum corneum } \\
\text { (lower) }\end{array}$ & $\begin{array}{c}\text { Stratum corneum } \\
\text { (upper) }\end{array}$ \\
\hline $\begin{array}{l}\text { Pan-keratin } \\
\text { (CK 1-8, 10, 14-16, 19) }\end{array}$ & $\begin{array}{l}\text { D } 1-2 \\
V 1-2\end{array}$ & $\begin{array}{l}\text { D } 2-4 \\
V 3-4\end{array}$ & $\begin{array}{l}\text { D } 0-2 \\
V 2-3\end{array}$ & $\begin{array}{l}\mathrm{D} 0 \\
\mathrm{~V} 2\end{array}$ & $\begin{array}{l}\mathrm{D} \text { (scale) } 0 \\
\quad V 2-4\end{array}$ \\
\hline CK1 & $\begin{array}{l}\text { D } 2-3 \\
V 1-2\end{array}$ & $\begin{array}{c}\mathrm{D} 4 \\
V 2-3\end{array}$ & $\begin{array}{l}\text { D } 2-3 \\
\text { V3 - } 4\end{array}$ & $\begin{array}{c}\text { D } 1-2 \\
\text { V0 }\end{array}$ & $\begin{array}{c}\mathrm{D} \text { (scale) } 0 \\
V 0-4\end{array}$ \\
\hline CK5 & $\begin{array}{c}\text { D } 0 \\
\text { V } 1-2\end{array}$ & $\begin{array}{c}\text { D } 0 \\
\text { V } 1-2\end{array}$ & $\begin{array}{c}\text { D } 0 \\
\text { V } 2-3\end{array}$ & $\begin{array}{c}\text { D } 0 \\
\text { V } 1-2\end{array}$ & $\begin{array}{l}\mathrm{D} \text { (scale) } 0 \\
\mathrm{~V} 0-4\end{array}$ \\
\hline CK6 & $\begin{array}{c}\mathrm{D} 0 \\
V 0-1\end{array}$ & $\begin{array}{l}\text { D } 0 \\
V 2\end{array}$ & $\begin{array}{l}\mathrm{D} 0 \\
V 3\end{array}$ & $\begin{array}{c}\mathrm{D} 0 \\
V 2-3\end{array}$ & $\begin{array}{l}\mathrm{D} \text { (scale) } 0 \\
\quad V 2-3\end{array}$ \\
\hline CK9 & $\begin{array}{c}\text { D } 0 \\
\text { V } 1-2\end{array}$ & $\begin{array}{c}\text { D } 0 \\
\text { V } 1-2\end{array}$ & $\begin{array}{c}\text { D } 0 \\
\text { V } 2-3\end{array}$ & $\begin{array}{l}\text { D } 0 \\
\text { V0 }\end{array}$ & $\begin{array}{c}\mathrm{D} \text { (scale) } 0 \\
\text { V0 }\end{array}$ \\
\hline CK10 & $\begin{array}{c}\text { D } 0 \\
V 1-2\end{array}$ & $\begin{array}{c}\text { D } 0 \\
V 2-3\end{array}$ & $\begin{array}{l}\text { D } 0 \\
\text { V3 }\end{array}$ & $\begin{array}{l}\text { D } 0 \\
\text { V1 }\end{array}$ & $\begin{array}{c}\mathrm{D} \text { (scale) } 0 \\
V 1\end{array}$ \\
\hline $\mathrm{AE} 13$ & $\begin{array}{l}\text { D } 0 \\
\text { V } 0\end{array}$ & $\begin{array}{l}\text { D } 0 \\
\text { V } 0\end{array}$ & $\begin{array}{l}\text { D } 2-4 \\
\text { V0 }\end{array}$ & $\begin{array}{l}\text { D } 0-1 \\
\text { V } 0\end{array}$ & $\begin{array}{c}\text { D (scale) } 0 \\
\text { V0 }\end{array}$ \\
\hline AE14 & $\begin{array}{c}\mathrm{D} 0 \\
V 2-3\end{array}$ & $\begin{array}{c}\mathrm{D} 0 \\
V 1-2\end{array}$ & $\begin{array}{c}\text { D } 0 \\
V 1-2\end{array}$ & $\begin{array}{l}\text { D } 0 \\
\text { V0 }\end{array}$ & $\begin{array}{c}\mathrm{D} \text { (scale) } 0 \\
\text { V0 }\end{array}$ \\
\hline
\end{tabular}

D, dorsal body region; $V$, ventral body region (in italics). Reaction intensities: 0 , no reaction; 1 , weak; 2 , medium; 3 , strong; 4 , very strong.

tion intensities exclusively the vital epithelial layers of the abdominal epidermis, and, additionally, the outer root sheath of the hair follicles found in the dermis of the ventral body region. Together with positive reactions for several acidic or basic-to-neutral (cyto)keratins, these findings support the view that scale development in the pangolin integument is in common with or of equal origin as the ventral nail matrix of the nail plate typical for other mammalian groups such as humans or laboratory mice..$^{10,11}$ The nail plate here also contains a mixture of soft and hard keratins suggesting that the precursor cells of hair cortex and nail plate share a major pathway of epithelial differentiation. This is indicated, for example, by the fact that during scale production in the dorsal pangolin integument, and nail development in the ventral nail matrix of humans, AE13 antibodies stained only the suprabasal epithelial cells. ${ }^{10,11,26,27}$

In total, the pangolin scales are well equipped to withstand even very strong mechanical loads as closely connected to the excellent soil-burrowing capacities of the species, ${ }^{6,828}$ including that the abrasive wear is compensated by a continuous production of hard hair keratins in the stratum granulosum of the dorsal epidermis (Figure 4a).

The evolutionary origin of the pangolin scales is still unknown, particularly regarding that the pluristratified epidermis of the vertebrate integument represents an external body cover, which creates the boundary between the organism and its environment. In all living vertebrates this specific epithelium is characterized by an outer layer with a more or less strong keratinisation based on a-keratins showing a homology in the different lineages, except for birds and reptiles which possess an
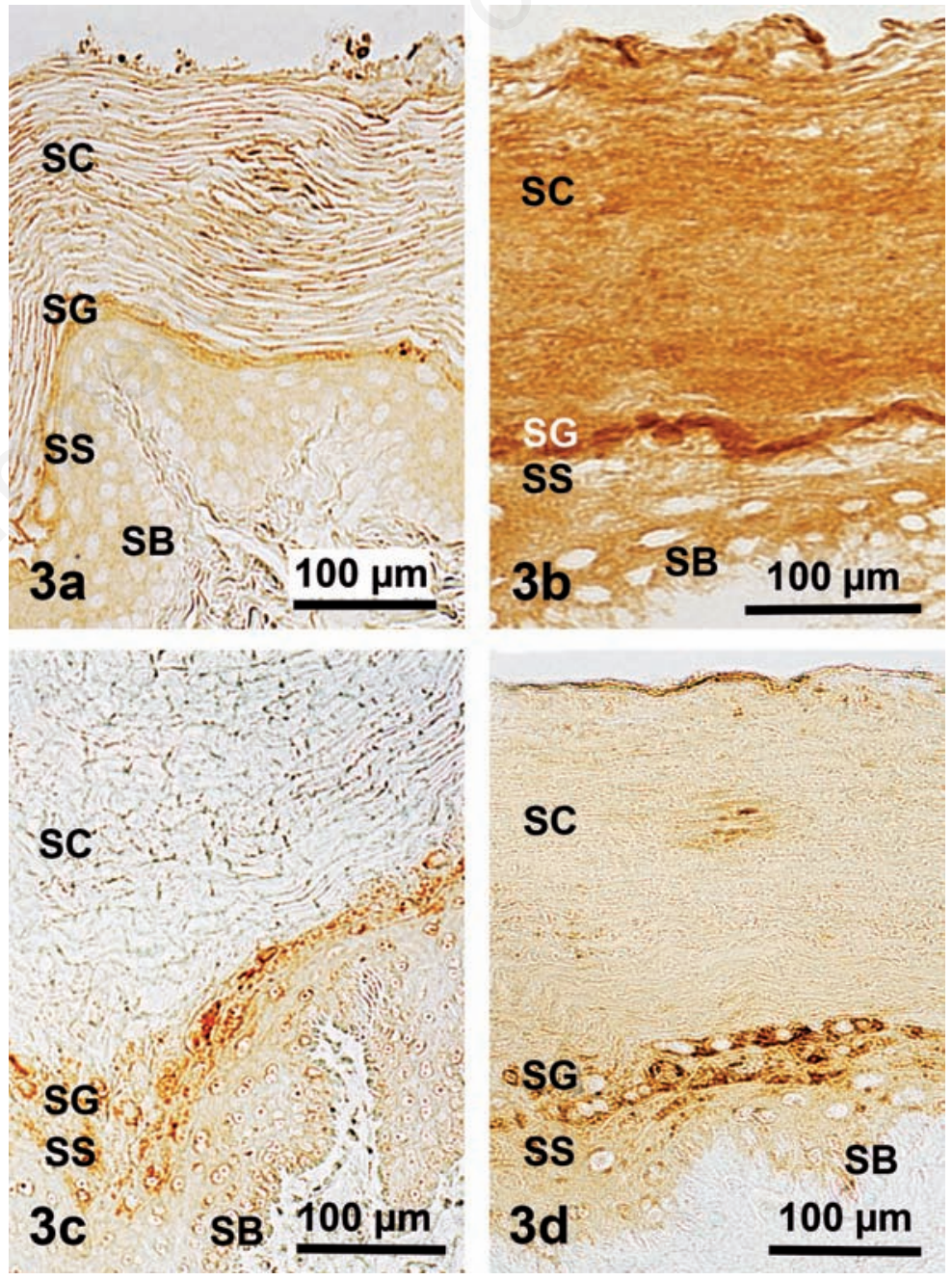

Figure 3. Demonstration of four specific epithelial (cyto)keratins in the soft abdominal epidermis of the Malayan pangolin; CK5 in (a), CK6 in (b), CK9 in (c), and CK10 in (d); it is shown that in the epidermis layers of this body part the reactions are rather weak to medium; DAB visualization. SB, stratum basale; SS, stratum spinosum; SG, stratum granulosum; SC, stratum corneum). 
additional capacity for hard b-keratins. ${ }^{29}$ Independent of the information given by the latter author, relevant ideas about the evolution of the dorsal scale wear of the small Order Pholidota are still missing, although it has been speculated about the pangolin scales to be homologous with primate nails but not with reptilian scales, and to have not derived from compressed hairs. ${ }^{6,30}$ Our findings demonstrated that the keratinisation of the pangolin scales is closely related to this event in nails and hairs, assuming that the evolution of the latter structures may have involved the cooption of pre-existing structural proteins., ${ }^{9,31,32}$ However, although the nail bed epithelium resembles the outer root sheath of the lower hair follicle, the epithelium of which serving as a slipping plane for the upward movement of the inner root sheath unit, ${ }^{33}$ these aspects are not generally applicable concerning the evolution of pangolin scales, particularly realizing the density and area of the dorsolateral
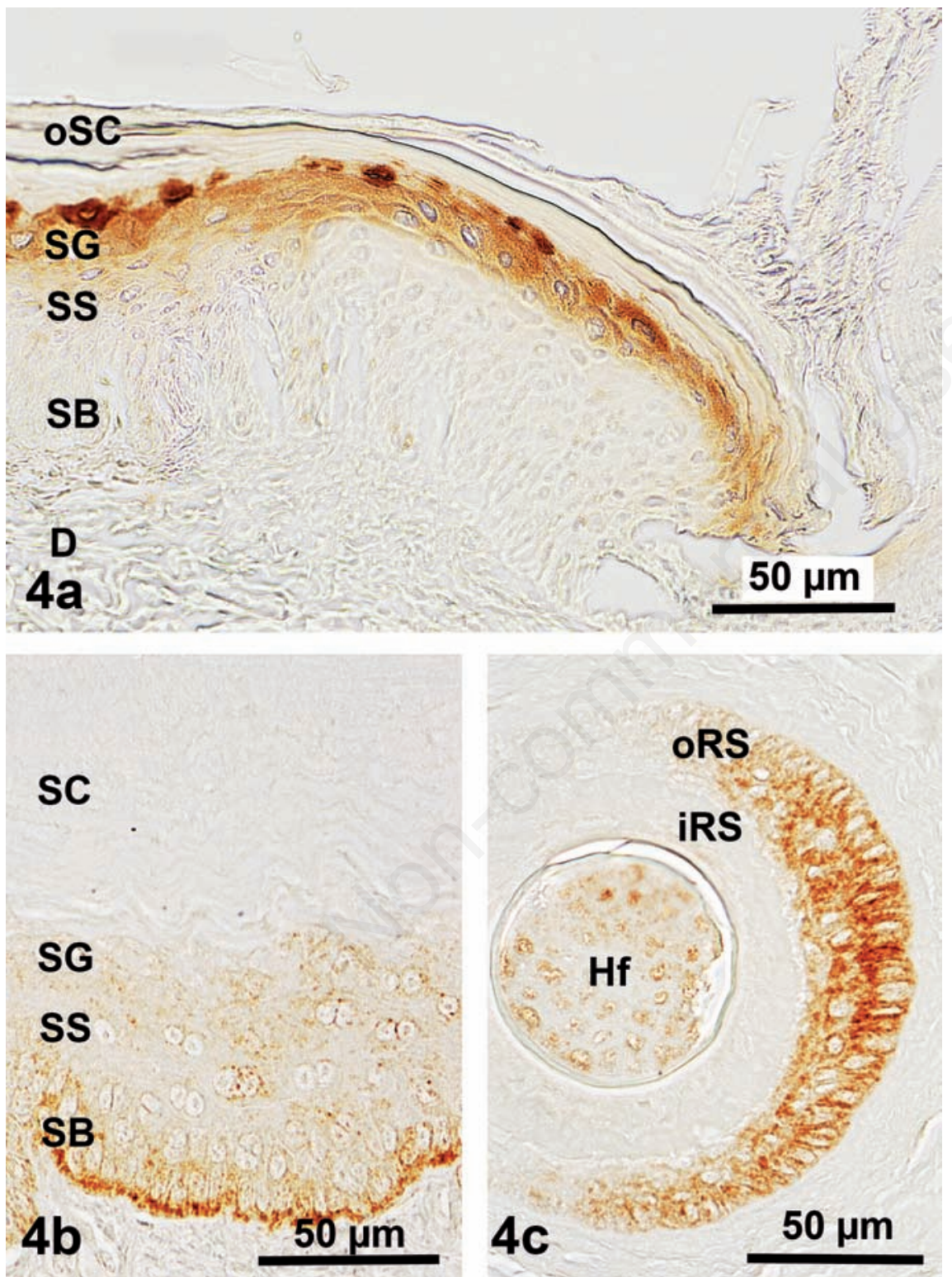

Figure 4. Demonstration of hard hair keratins in the epidermis and dermis of the Malayan pangolin; distinctly positive reactions for $\mathrm{AE} 13$ are found in (a) the layers of the vital epidermis of a scale hinge region, particularly the stratum granulosum, for AE14 in (b) the ventral body region, but somewhat restricted to the stratum basale of the ventral body region; moreover, positive staining for AE14 also concentrated (c) in the outer root sheath of hair follicles; DAB visualization. SB, stratum basale; SS, stratum spinosum; SG, stratum granulosum; SC, stratum corneum; oSC, outer stratum corneum; oRS, outer root sheath; iRS, inner root sheath; $\mathrm{D}$, dermis.

scale cover. Moreover, only in the Asiatic pangolin species hairs grow out from behind each scale (see Grassé ${ }^{34}$ page 1269, Figure 1204B), a feature that was also observed at the skin scales of the tail of several adult rodent species, such as Rattus spec., Mus musculus or Myocastor coypus, and one Scandentia species, Ptilocercus lowii (for literature and figures see Ihle et al., ${ }^{35}$ pp 42-43, Figures 43-45; Meyer and Roehrs, ${ }^{36}$ page 249, Figure 5B1-2). With regard to this parallel cases, which may be a specific remnant of the early development of the Order Rodentia and the small Order Scandentia, it is very interesting to know that the soft horny scales arise from a narrow epidermal germinal base ${ }^{37}$ However, it should not be forgotten that during embryological development such close relations of horny scales and hairs could likewise be detected in two old (Cretaceous and Paleocene) Orders, the Insectivora (example: back of Centetes spec.) and the Cingulata (example: lower leg of Dasypus novemcinctus), as shown by Schimkewitsch $^{38}$ (page 73, Figures 88-89).

In conclusion, the tail scales of the Rodentia and the Scandentia, a sister to the Glires (lagomorphs and rodents), $, 39,40$ and the unique hard horny scales of the Pholidota may have been evolved at the same time as a homologous structural integumental peculiarity during the transition between Paleocene and Eocene (53-54 Mya), and possibly from the same origin, i.e., an epidermal germinal base, probably starting at the tail root and projecting forward to the head. In the Pholidota, this acquisition may have been promoted specifically by the strong monophyly of the crown clade of pangolins, the Manidae, ${ }^{4}$ whereas the equally monophyletic rodents concentrated on the development of a tremendous species diversity based on extensive genome reshuffling, to become the most abundant and diversified Order comprising almost the half of all species of living mammals. Diversification in the monophyletic Scandentia started later during the Miocene (6 Mya), and was less effective regarding species production but successful in the colonization of new habitats, including island hopping and landbridge conquest. ${ }^{4,39,41-43}$

\section{References}

1. Murphy WJ, Eizirik E, O’Brien SJ, Madsen 0, Scally M, Douady CJ, et al. Resolution of the early placental mammal radiation using bayesian phylogenetics. Science 2001;294:2348-51.

2. Beck RMD, Bininda-Emonds ORP, Cardillo M, Liu FGR, Purvis A. A higher-level MRP supertree of placental mammals. BMC Evol Biol 2006;6:93. 
3. Francis CM. A field guide to the mammals of South-East Asia. New Holland Publ., London, UK, 2008.

4. Gaudin TJ, Emry RJ, Wible JR. The phylogeny of living and extinct pangolins (Mammalia, Pholidota) and associated taxa: A morphology based analysis. J Mammal Evol 2009;16:235-30.

5. Meyer W, Liumsiricharoen M, Hornickel I, Suprasert A, Schnapper A, Fleischer LG. Demonstration of substances of innate immunity in the integument of the Malayan pangolin (Manis javanica). Eur J Wildl Res 2010;56:287-96.

6. Mohr E. [Schuppentiere (Neue Brehm Buecherei 284)]. [Book in German]. Ziemsen Publ., Wittenberg, Germany, 1961.

7. Tong J, Ren L-Q, Chen B-C. Chemical constitution and abrasive wear behaviour of pangolin scales. J Material Sci Lett 1995;14: 1468-70.

8. Tong J, Ma Y-H, Ren L-Q, Li J-Q. Tribological characteristics of pangolin scales in dry sliding. J Material Sci Lett 2000;19:569-72.

9. Vandebergh W, Bossuyt F. Radiation and functional diversification of alpha keratins during early vertebrate evolution. Mol Biol Evol 2012;29:995-1004.

10. Lynch MH, O'Guin WM, Hardy C, Mak L, Sun TT. Acidic and basic hair/nail ("hard") keratins: Their colocalization in upper cortical and cuticle cells of the human hair follicle and their relationship to "soft" keratins. J Cell Biol 1986;103:2593-606.

11. Perrin C, Langbein L, Schweizer J. Expression of hair keratins in the adult nail unit: an immunohistochemical analysis of the onychogenesis in the proximal nail fold, matrix and nail bed. Brit $\mathrm{J}$ Dermatol 2004;151:362-71.

12. Moll R, Divo M, Langbein L. The human keratins: biology and pathology. Histochem Cell Biol 2008;129:705-33.

13. Coulombe PA, Ma L, Yamada S, Wawersik M. Intermediate filaments at a glance. J Cell Sci 2001;114:4345-7.

14. Jamora C, Fuchs E. Intercellular adhesion, signalling and the cytoskeleton. Nature Cell Biol 2002;4:101-8.

15. Morita K, Miyachi Y, Furuse M. Tight junctions in epidermis: from barrier to keratinization. Eur J Dermatol 2011;21:12-7.

16. Boeck P. [Romeis Mikroskopische Technik]. [Book in German]. 17th ed. Urban \& Schwarzenberg, Muenchen, Germany, 1989.

17. Hornickel IN, Kacza J, Schnapper A, Beyerbach M, Schoennagel B, Seeger J, et al. Demonstration of substances of innate immunity in the esophagus epithelium of domesticated mammals. Part I - Methods and comparative fixation evaluation. Acta Histochem 2011;113:163-74.

18. Fuchs E. Keratins and the skin. Annu Rev Cell Biol 1995;11:123-53.

19. Reichelt J, Buessow H, Grund C, Magin TM. Formation of a normal epidermis supported by increased stability of keratins 5 and 14 in keratin 10 null mice. Mol Biol Cell 2001;12:1557-68.

20. Holbrook KA Biologic structure and function: Perspectives on morphologic approaches to the study of the granular layer keratinocyte. J Investig Dermatol 1989;92:84S-104S.

21. Meyer W, Neurand K. A comparative scanning electron microscopic view of the integument of domestic mammals. Scann Microscopy 1987;1:169-80.

22. Meyer W, Schmidt J, Kacza J, Busche R, Naim HY, Jacob R. Basic structural and functional characteristics of the epidermal barrier in wild mammals living in different habitats and climates. Eur J Wildl Res 2011:57: 873-85.

23. Chan Y, Anton-Lamprecht I, Yu QC, Jackel A, Zabel B, Ernst JP, et al. A human keratin 14 "knockout": the absence of K14 leads to severe epidermolysis bullosa simplex and a function for an intermediate filament protein. Genes Development 1994; 8:2574-87.

24. Hutton E, Paladini RD, Yu Q-Ch, Yen M, Coulombe PA, Fuchs E. Functional differences between keratins of stratified and simple epithelia. J Cell Biol 1998;143:48799.

25. Kurokawa I, Takahashi K, Moll I, Moll R. Expression of keratins in cutaneous epithelial tumors and related disorders - distribution and clinical significance. Exp Dermatol 2011;20:217-28.

26. Kitahara T, Ogawa H. Cultured nail keratinocytes express hard keratins characteristic of nail and hair in vivo. Arch Dermatol Res 1992;284:253-56.

27. De Berker D, Wojnaroska F, Sviland L., Westgate GE, Dawber RPR, Leigh IM. Keratin expression in the normal nail unit: markers of regional differentiation. Brit $\mathrm{J}$ Dermatol 2000;142:89-96.

28. Tong J, Lue T-B, Ma Y-H, Wang H-K, Ren LQ, Arnell RD. Two-body abrasive wear of the surfaces of pangolin scales. J Bionic Engin 2007;4:77-84.

29. Dhouailly D. A new scenario for the evolutionary origin of hair, feather, and avian scales. J Anat 2009;214:587-606.

30. Spearman RIC. On the nature of the horny scales of the pangolin. J Linn Soc (Zool)
$1967 \cdot 46 \cdot 267-73$

31. Alibardi L, Toni M, Dalla Valle L. Hard cornification in reptilian epidermis in comparison to cornification in mammalian epidermis. Exp Dermatol 2007;16:961-76.

32. Eckhart L, Dalla Valle L, Jaeger K, Ballaun C, Szabo S, Nardi A, et al. Identification of reptilian genes encoding hair keratin-like proteins suggests a new scenario for the evolutionary origin of hair. PNAS 2008; 105:18419-23.

33. Winter H, Langbein L, Praetzel S, Jacobs M, Rogers MA, Leigh IM, et al. A novel human type II epithelial keratin, K6hf, specifically expressed in the companion layer of the hair follicle. $J$ Investig Dermatol 1998;111:955-62.

34. Grassé PP. [Mammifères - Pholidota]. In: PP Grassé (ed) Traité de Zoologie, Vol 17 [Book in French]. Masson Publ., Paris, 1955, pp 1268-84.

35. Ihle JEW, van Kampen PN, Nierstrasz HF, Versluys J. [Vergleichende Anatomie der Wirbeltiere.] [Book in German]. Springer Publ., Berlin, Germany, 1927.

36. Meyer W, Roehrs M. [Von der Reptilienschuppe zu Feder und Haar - zur Evolution der Hautanhangsorgane]. [Article in German]. Dtsch Tieraerztl Wschr 1986;93:245-51.

37. Walker EP. Mammals of the world, vol 1. John Hopkins Publ., Baltimore, USA, 1964.

38. Schimkewitsch W. [Lehrbuch der Vergleichenden Anatomie der Wirbeltiere]. [Book in German]. W Schwei zerbarth Publ., Stuttgart, Germany, 1910.

39. Huchon D, Madsen 0, Sibbald MJJB, Ament K, Stanhope MJ, Catzeflis F, et al. Rodent phylogeny and a timescale for the evolution of Glires: Evidence from an extensive taxon sampling using three nuclear genes. Mol Biol Evol 2002;19:105365.

40. Janecka JE, Miller W, Pringle TH, Wiens F, Zitzmann A, Helgen KM, et al. Molecular and genomic data identify the closest living relatives of primates. Science 2007; 318:792-4.

41. Olson LE, Sargis EJ, Martin RD. Intraordinal phylogenetics of treeshrews (Mammalia: Scandentia) based on evidence from the mitochondrial 12S rRNA gene. Mol Phylogenet Evol 2005;35:656-73.

42. Roberts TE, Lanier HC, Sargis EJ, Olson LE. Molecular phylogeny of treeshrews (Mammalia: Scandentia) and the timescale of diversification in Southeast Asia. Mol Phylogenet Evol 2011;60:358-72.

43. Romanenko SA, Perelman PL, Trifonov VA, Graphodatsky AS. Chromosomal evolution in Rodentia. Heredity 2012;108:4-16. 